\title{
PRICE FORMATION IN THE OTC CORPORATE BOND MARKETS: A FIELD STUDY OF THE INTER-DEALER MARKET
}

BY

ANTHONY SAUNDERS

ANAND SRINIVASAN

And

INGO WALTER*

October 1998

[Preliminary]

*Dept. of Finance Stern School of Business, NYU 44 West $4^{\text {th }}$ Street New York, NY 10012

Contact:

Tel: 212-998-0711

Fax: 212-995-4232

E-mail: asaunder@stern.nyu.edu 


\begin{abstract}
This is the first exploratory field study of the U.S. inter-dealer OTC corporate bond market. We do this by analyzing the trades of a major bond dealer and through interviews with personnel at the trading desk of this dealer. We document the competitive structure of the market in terms of the number of active dealers, the mechanism used to facilitate trades etc. We find that the mechanism of trading closely resembles a first price sealed bid auction. The number of active dealers is quite small - only 9 dealers account for a large fraction of the trades. We examine potential differences between different segments of the market. We develop a measure of competition for this bidding market based on the theory of auctions. This is the difference between the best and second best bid in a given trade. Our measure of competition indicates that competition is highest in US investment grade corporate bonds and lowest in junk bonds. We also examine the effect of size of the trade on this measure of competition. Surprisingly, large trades do not suffer from any adverse market impact. Lastly, we examine the effect of exclusion of individual bidders on the level of competition. The effect does not appear very large.
\end{abstract}




\section{Introduction}

While the Corporate bond market has a market value close to $\$ 3$ trillion, empirical research into price and return formation in this market has been relatively sparse compared to equity markets. There are two reasons for this. First, while some corporate bonds trade on the NYSE and AMEX exchanges, they tend to be odd-lots accounting for no more than $2 \%$ of market volume (see Nunn et al (1986), Warga (1991), Warga and Welch (1993)). Second, data quotes on OTC trades tend to be diffuse and based on matrix valuation rather than on actual trades (such as those produced by IDC in association with S and P and Moody's). A few studies have sought to use real quotes from dealers such as Lehman Bros. (see, Warga and Welch (1993)) and find quite surprising disparities between matrix prices and actual dealer quotes.

To our knowledge, no study has analyzed the dynamics of price formation in the U.S. Corporate bond dealer market. Specifically, questions such as how many dealers bid for large blocks of OTC placed corporate bonds? is there a difference in the bidding behavior for investment grade versus non-investment grade bonds? And, what is the link between price determination and the number of bidders (i.e., how competitive is the market?) have yet to be analyzed. Indeed, while we know a lot about the competitive structure of US equity markets we know very little about the competitive structure and pricing dynamics of the US corporate bond markets. Indeed, the lack of transparency in pricing has been of great concern to the SEC -especially in periods of high volatility as recently experienced. Specifically, at the 
SEC's request NASD is planning to set up an electronic network to report and distribute immediately prices on OTC corporate bond trades. ${ }^{1}$

As a first step in closing this knowledge gap we carried out a field study of price determination in the OTC corporate bond market with the support of one major corporate bond trader. ${ }^{2}$ In the next section (Section 2), we provide a general description of the OTC bond market. In Section 3, we describe our database while in Section 4 we provide descriptive statistics of the sample. In Section 5, we provide some evidence of the competitive structure of the market. Section 6 concludes.

\section{Description of the market}

Most of the participants in the OTC bond market are large traders(dealers), usually money managers, who trade on behalf of their institutional clients. There are also inter-dealer brokers who are both on the buy and sell sides and essentially act similar to market makers in the stock market. The inter-dealer brokers provide anonymity to the dealers who make trades on behalf of their clients. Dealers can bypass the inter-dealer brokers and directly trade with other dealers for issues that they know that a given dealer has an interest in.

The following description applies to the asset manager/dealer who provided the trading data. Clients of the asset management firm along with the asset managers decide on a portfolio strategy regarding risk and return. This includes decisions on what type of bonds to hold ( high risk, low risk, foreign /domestic ...). Once a decision on the general portfolio strategy is made, the client gives the asset manager complete discretion in trading decisions. The asset manager then decides what bonds

\footnotetext{
${ }^{1}$ See, New York times "NASD to Set up Network to Report Data on Bonds," September 10, 1998.

${ }^{2}$ For proprietary and competitive reasons names of specific dealers cannot be disclosed in this paper.
} 
to buy or sell, what type to hold, what maturity (duration) to hold etc.. Periodically, the client reviews the account's performance and also indicates to the asset manager any desired change in the risk/return characteristics.

The dealer working for the asset manager does not initiate trades on his/her own account. All of the asset manager's trades are on behalf of his clients, with the asset manager getting a fee based on the amount of assets managed. The performance of the portfolio(account) is usually benchmarked to appropriate bond indices. The asset manager decides on the names and maturity of the bonds that are needed in different accounts. These are then given to the trader who executes the order. The trader has discretion with respect to the timing and the price of the trade. Basically, it is the trader who decides whether an issue is worth buying at a particular price or not. In a few cases, the issues that are desired may not be available in the market. In this case, the trader, with the consent of the account manager, can buy alternative bonds with similar risk, return and maturity characteristics.

The trader has access to different data providers. These providers (such as Telerate and Bloomberg) provide data on treasury rates and prices, including actual trades of treasury bonds, spot and future rates and stock market information. In addition, they also have access to proprietary trading models to calculate analytics of different bonds. A few traders in the market (and inter-dealer brokers generally) have a screen based information system for actual trades of corporate bonds as well. (Similar to the government bond service mentioned previously). However, the dealer examined in our study does not have access to this service. Such information is more critical to the interdealer brokers and subscribing to this normally involves a strategic 
decision to become one. This decision is currently under review at the given asset management company.

The typical procedure would be for the trader to initiate contact with other dealers or inter-dealer brokers who he knows are interested in a bond. Those counter-parties that are interested submit quotes to the dealer. These quotes are not legally binding. However, reputational reasons prevent dealers from making bids that they cannot honor. The dealer has a fiduciary responsibility to get the best quote ${ }^{3}$ and to treat all accounts equally. He does not know the client's identity. He only knows the account number(s) for which a given trade is made. In case the dealer is unable to buy or sell the entire amount required, he allocates the amount actually traded in proportion to the amount requested pro-rata. The dealer records all quotes in his trade book. The dealer may solicit additional bids if he thinks that the best bid that he has received is not competitive. The dealer, however, does not allow any participant to submit a bid more than once. In case of very large blocks, the trader may initiate simultaneous offers with different parties. Usually, this is when one party has already submitted a firm quote for a major part of the issue, and the dealer needs to buy/sell the remaining part of the issue.

A trade can be initiated by any dealer. If initiated by another dealer, the trader decides if the given issue fits the needs of at least some of their clients. In case of companies that the trader is unfamiliar with, the research department assists the

\footnotetext{
${ }^{3}$ The Employee Retirement Security Income Act (ERISA), which governs a large portion of retirement money invested, requires this fiduciary duty. Since retirement assets are primarily invested in the bond market, it is plausible to assume that this fiduciary requirement holds for most dealers in the market.
} 
trading desk in this evaluation. Once this is done the dealer consults the asset managers. If the go-ahead to buy is given, the trader accepts the trade.

A typical counter-party submits a bid within 1-2 minutes of the getting a request from the dealer. This happens in many trades when both sides are familiar with the details of the particular issue and the given bond is a straight bond with no special provisions. However, in the case of trades where the bonds have complex features such as call or put provisions, sinking fund provisions, the submission time for a bid by a given counter-party after being requested is usually about 10 minutes. In this time, the traders run their proprietary analytic software. In case of very illiquid bonds, a trade can take as long as a day. This also happens if the amount to be traded is large, where large is defined as greater than $\$ 20$ million. One of the reasons for this difficulty in trading large blocks is relatively low level of short selling in this market. Dealers and even inter-dealer brokers are reluctant to short more than $\$ 10$ million in notional amounts. ${ }^{4}$ Trading time is also increased in times of high stock or bond market volatility. Trades are mostly conducted in terms of a spread over a comparable maturity treasury. A typical quote for an issue would thus be "IBM series A 5 year maturity for 80 basis points over 5 year treasury yield". Most of the market participants in this market follow this convention.

\section{The Data Base}

The analysis is based on a randomly selected sample of bond trades conducted by a major asset manager/dealer in the OTC corporate bond market during the period

\footnotetext{
${ }^{4}$ Given that Long Term Capital Management's recent financial woes can be attributed to shorting and playing on interest rate spreads, this reluctance seems well justified. ("Bailout blues", The Wall Street Journal, September 25,1998)
} 
January 1, 1997 to November 28, 1997. The following data were collected from the dealer's trading book:

- Name of the issuer

- Face value of the trade

- Coupon

- Time to maturity

- Bid/offer prices

- Trade date and time

- Settlement date

- Name of winning counterparty

- Price of winning bid/offer, hereafter referred to as "best bid"

- Names of other bidders

- Prices quoted by other bidders

Trading occurred by successive "auctions" during any given day. For example, a block of corporate bonds of a specific issuer were posted for sale by one or more portfolio managers and telephone bids were received from other dealers. The highest bidder received the block. (An offer is defined as an offer to sell securities to the dealer. Thus, the lowest among the submitted prices is chosen).

The method of transaction-selection examined every fifth trade from the dealer's trade book. There were two exceptions to this data-selection rule:

- If the fifth trade in sequence was part of a bond swap contract.

- If the fifth trade involved only one bid/offer price (i.e., only one trader showed an interest in the transaction) ${ }^{5}$.

In such cases, the trade was excluded from the sample and the next trade that satisfied the above criteria was selected. By excluding such trades, it was possible to concentrate on bonds whose competition was active.

\section{Descriptive Statistics of the Sample}

\footnotetext{
${ }^{5}$ We randomly selected one month, the month of November and found that the percentage of single bid trades in this month was about $30 \%$ of the total number of trades in this month.
} 
The characteristics of the sample of trades is shown in Tables 1. As noted above, the sample comprises every fifth trade (with more than one bid) conducted by a large corporate bond dealer's trading desk over an 11-month period from January to November 1997. A total of 987 trades were analyzed that received more than a single bid.

As can be seen in Table 1, over and above the winning bid, there were an average of 2.44 additional bids per trade, with the most frequent number of additional bids being 2 - i.e., three bidders in all, with one winning bidder and two unsuccessful bidders. The histogram in Figure 1 shows the distribution of additional bidders.

The total number of trades encompassed three different types of bonds: corporate investment-grade bonds, emerging market bonds, and high-yield securities (defined as those corporate bonds with yields $2 \%$ or more above similar-maturity Treasury bonds). There are 373 corporate bond trades in the sample, 478 emerging market bond trades and 136 high-yield securities trades. Measured by number of additional bids (to the winning bid) received per trade, corporate bond trades were the most competitive (2.8 additional bids per trade), followed by emerging market bonds (2.32) and high-yield bonds (1.9).

The sample can also be broken down in terms of the maturity of the bonds traded. The number of short-term (less than 1-year maturity) securities transactions analyzed was 21, medium-term securities (1 year to 10 years) 552 , and longer-term securities (maturities greater than 10 years) 414. In terms of additional bids per trade, they varied from an average high of 2.71 for short-term securities to a low of 2.39 for 
medium-term securities. From Figure 2, we can see that over 92\% the trades were below $\$ 10$ million.

\section{Competitive Structure}

One way to analyze the competitive structure of the OTC corporate bond market is to look at measures of bid-spreads. The bidding mechanism in the OTC market for large trades in corporate bonds is closest to the first price sealed bid auction mechanism. It has been shown that the English auction, the Dutch auction, the second price sealed bid auction and the first price auction yield the same revenue to the seller on average (see, the revenue equivalence theorem of Vickery (1961)). We know that for second price auctions, increasing the number of bidders increases the revenue of the seller on average (Holt (1979), Harris and Raviv (1981)). Further, as the number of bidders increase, the second highest bidder tends to use the highest possible valuation, i.e., the price difference between best and second best bidder gets smaller. Since an increase in the number of bidders increases the level of competition and also reduces the price spread, or difference, between the best and second best bids

-- this latter spread appears to be a reasonable measure of the competitiveness of this auction-type market. Since all four major auction mechanisms have similar average revenue characteristics under risk neutrality (Vickery (1961)) we assume below that the price difference between the best and second best bids can be used as a measure of competitive conditions in the OTC corporate bond market.

Here (in Table 2) we report the differences between (i) the best (winning) bid and the next best bid (ii) the best (winning) bid and the average of the non-winning bids and (iii) the best (winning) bid and the worst bid. 
From Table 2, it is evident that the difference between the winning bidder and the second-best bidder is an average of 15.3 basis points (or $0.153 \%$ ). In terms of dollars per trade, this averages $\$ 5,271$. Aggregated over the 987 trades in the field sample this amounted to $\$ 5,202,372$ during the 11 -month period examined. The price differences between the best to average losing bidder and best to worst bidder were respectively 23.7 and 34.9 basis points. Table 3 breaks these data down by type of bond while Table 4 breaks these data down by maturity. As can be seen from Tables 1 and 3, the high-yield market is by far the thinnest in terms of number of bidders and largest in price dispersion across bidders. Interestingly, emerging market price formation and bidding activity appears to be closer to that of investment grade corporate bonds than high yield domestic bonds.

An alternative way to analyze these data is to examine the correlation between the number of additional bidders and the difference between the winning bid and the second best bid. In particular, do price differences between the best and next best bid fall in the presence of a larger as opposed to a smaller number of alternative bidders?

The correlation matrix shown in Table 5 indicates that there is a correlation coefficient of -.154 between the number of bidders and the dollar-amount difference between the winning and second best bids. Moreover, an increase of one additional bidder reduces the price difference between the best and second best bidder by $23.6 \%$.

This generally inverse relationship between the number of bidders and the difference between the best and the next best bid price is also confirmed by regression tests. Table 6a shows a linear regression of the number of bidders on the best-second- 
best bid differential. It can be inferred that an increase in one bidder reduces this price spread by $\$ 1,673$ per trade. We also tested various non-linear specifications of the relationship between bid spreads and number of bidders. For example, a log-log model and a power function model. Both showed an inverse relationship between the number of bidders and the (winning bid-second-best bid) measure. We also test the same hypothesis by looking at the percent difference between the best-second best bids, while controlling for any effect resulting from the size of the trade. The relation continues to be negative. More interestingly, the best-second best spread is negatively related to the size of the trade. These results are shown in Table $6 \mathrm{~b}$.

To better investigate the impact of large trades, we split the sample into trades less than or equal to $\$ 10$ million and trades greater than $\$ 10$ million. This division is admittedly arbitrary. It is based on conversation with traders who felt that trades less than $\$ 10$ million are definitely not large blocks and trades greater than 20 million are definitely large blocks. Further, in the sample, more than $90 \%$ of the trades are for less than $\$ 10$ million. Based on this split of the sample, we conducted a t-test of differences in mean values of the number of bids, the spread between the best and second-best and the spread between the best and the worst. The results are shown in Table 7. Firstly, there is no significant difference in the number of bids between the large block and regular trade sample. Secondly, both the best-second best and the best-worst spreads are significantly lower for the large trade sample. Thus, it appears that large trades in this market are not at a significant competitive disadvantage relative to normally sized trades. That is, a large trade does not appear to convey any 
special adverse market information. As a result, overall "economies of scale" in trading appear to benefit the large trades in terms of the best-second best spread. ${ }^{6}$

We also analyzed the effects on prices and bidding of successively excluding each of the nine largest counterparties to the dealer's trading desk - "largest counterparties" being defined as firms that won more than $5 \%$ of the sample of bids. The estimated effects on bid spread from this "successive-exclusion" scenario are shown in Table 8.

In the sample of trades used Bidder 1 was the most successful bidder, winning 150 out of the 987 trades. Excluding Bidder 1 as a counterparty in these 150 trades (and taking the next best bid as the winning bid) results in a value-weighted additional cost of 16.1 basis points per trade. Excluding Bidder 2 (100 winning trades) results in an additional cost of 15.1 basis points per trade. The ninth most successful bidder (Bidder 9) won 55 bids, with an average additional cost of 13.2 basis points from exclusion. Thus, exclusion of bidder 1 from this market would on average result in an increase in the execution costs of $0.024 \%$. This was calculated as follows: The fraction of trades in which the bidder submitted the best bid multiplied by the best-second best spread in those trades for which the given bidder submitted the best bid. For bidder 1 , then this is $150 / 987$ multiplied by $0.161 \%$. For bidder 9 , this effect is $.007 \%$.

\section{Conclusion}

This is the first paper to analyze large OTC trades and price formation in the US corporate bond market. This study is unique in that it utilizes actual transaction prices and bids submitted for block trades of corporate bonds.

\footnotetext{
${ }^{6}$ This is in contrast to the equity markets where larger trades (both on the exchange floor and in the upstaris market) generally have higher total price impact. See, for example, Madhavan and Cheng(1997)
} 
The institutional features of this market are documented. The market seems to be characterized by a few large traders acting mostly on behalf of institutional clients. An inter-dealer market similar to the one in government bonds exists. It appears that the trading mechanism closely resembles that of a first price sealed bid auction.

Using the trading book of a major dealer over an 11-month period in 1997, we analyzed the competitiveness of the market in terms of the number of bids received for each trade and the differences between the different types of bonds such as corporate, high-yield and emerging market bonds. We also developed a measure of competition for this market. This was the difference between the best and second best bid on any trade. The theoretical justification for using this measure is grounded in auction theory literature.

It was found that the average number of bidders is quite small with nine major counter-parties accounting for a major fraction of trades. Despite the small number of counter-parties, the market is quite competitive. The spreads are approximately $0.15 \%$ between the best and second best trades for the whole sample. Interestingly the OTC market for emerging market bonds appeared to be more competitive than domestic high yield bonds. Further, additional bidders appeared to have a material pro-competitive effect on the observed bid difference between the best and second best bids.

Finally, large trades did not seem to suffer from the disadvantages that are now well documented for large stock trades. The difference between the best and secondbest decreased with increased trade size. This was confirmed by both regression analysis and with a split sample t test. 


\section{REFERENCES}

1. Nunn, K.P., J. Hill and T. Schneiweiss "Corporate Bond Price Data Sources Return/Risk Measurement" Journal of Financial and Quantitative Analysis, Vol. 21, No. 2, June 1986 pp. 197-208.

2. Harris, M. and Raviv, A. "Allocation Mechanisms and the Design of Auctions," Econometrica, November 1981, 49(6), pp. 77-99.

3. Holt, C.A., Jr. "Uncertainty and the bidding for Incentive Contracts" American Economic Review, September 1979, 69(4), pp. 697-705

4. Madhavan, Ananth and Minder Cheng "In search of liquidity: Block trades in the upstairs and downstairs markets," The Review of Financial Studies, Spring 1997, 10(1), pp.175-203.

5. Vickery, W. "Counter Speculation, Auctions, and Competitive Sealed tenders," Journal of Finance, March 1961, pp. 8-37.

6. Warga, Arthur D., "Corporate bond price discrepancies in the dealer and exchange markets", Journal of Fixed Income, December 1991, pp. 7-16.

7. Warga, A and I. Welch "Bondholder Losses in Leveraged Buyouts" Review of Financial Studies, Vol. 6, No. 4, 1993 pp. 959-982. 


\section{Table $6 \mathrm{~b}:$ Regression of best-second best spread vs trade size and nbid}

\section{SUMMARY OUTPUT}

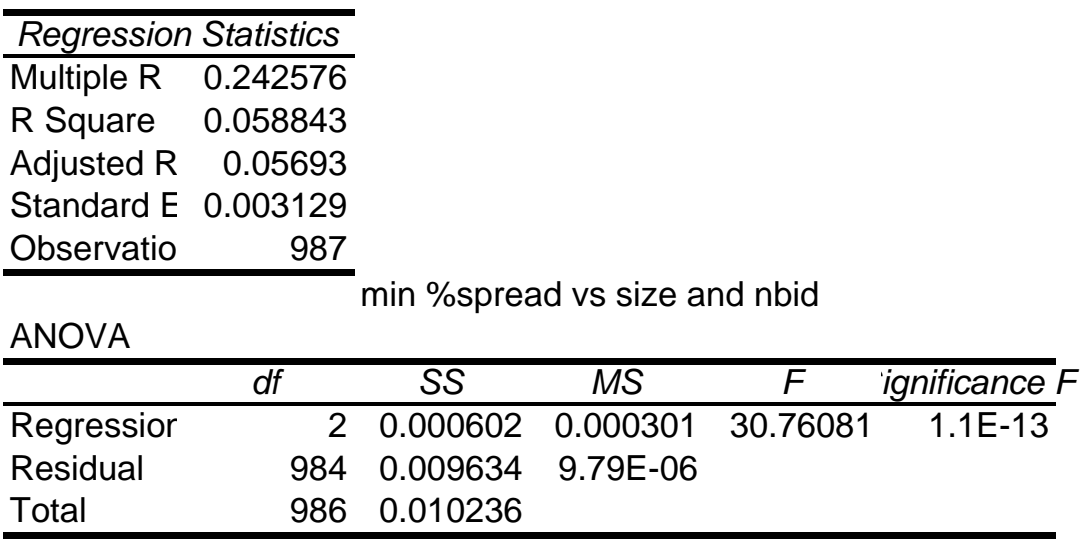

\begin{tabular}{lrrrrrrrr}
\hline & Coefficientstandard Err & \multicolumn{1}{c}{$t$ Stat } & \multicolumn{1}{c}{$P$-value } & Lower 95\% Upper 95\%.ower 95.0\%/pper 95.0\% \\
\hline Intercept & 0.003523 & 0.000237 & 14.85886 & $3.29 \mathrm{E}-45$ & 0.003057 & 0.003988 & 0.003057 & 0.003988 \\
trade size & $-3.68 \mathrm{E}-11$ & $2.04 \mathrm{E}-11$ & -1.797534 & 0.072557 & $-7.69 \mathrm{E}-11$ & $3.37 \mathrm{E}-12$ & $-7.69 \mathrm{E}-11$ & $3.37 \mathrm{E}-12$ \\
nbid & -0.000639 & $8.49 \mathrm{E}-05$ & -7.523616 & $1.2 \mathrm{E}-13$ & -0.000805 & -0.000472 & -0.000805 & -0.000472 \\
\hline
\end{tabular}

